\title{
A DESCARACTERIZAÇÃO DE BARRAGENS DE REJEITO E O PLANO DE FECHAMENTO DE MINA COMO INSTRUMENTOS DE MITIGAÇÃO DE RISCOS NA MINERAÇÃO
}

\author{
Romeu Thomé1 \\ Escola Superior Dom Helder Câmara (ESDHC) \\ Luiz Gustavo Gonçalves Ribeiro² \\ Escola Superior Dom Helder Câmara (ESDHC)
}

\section{RESUMO}

A mineração tem como características a modificação do meio ambiente e a geração de riscos socioambientais, visualizados nitidamente a partir da ocorrência de desastres que marcaram negativamente a trajetória da exploração mineral no Brasil. O objetivo do trabalho é analisar, sob a perspectiva dos princípios da prevenção e do poluidor-pagador, a eficácia das normas que vedaram a utilização do método de alteamento de barragens denominado a montante e determinaram a descaracterização de barragens de rejeitos, além daquelas que preveem o adequado fechamento de mina e a recuperação da área degradada pela mineração. A pesquisa se valeu de dados primários e secundários consistentes na análise de textos legislativos e doutrina. Foi possível concluir que as normas jurídicas são relevantes instrumentos para a implementação da internalização das externalidades negativas, na medida em que exigem dos empreendimentos minerários a adoção de ações preventivas, especialmente no que tange à recuperação das áreas degradadas e à mitigação dos riscos inerentes às barragens de rejeito.

Palavras-chave: barragens; externalidades negativas; internalização; mineração; riscos.

1 Pós-doutor pela Université Laval, Canadá. Doutor em Direito pela Pontifícia Universidade Católica de Minas Gerais (PUC-MINAS). Mestre em Direito pela Universidade Federal de Minas Gerais (UFMG). Professor do Mestrado e do Doutorado em Direito Ambiental e Desenvolvimento Sustentável da ESDHC. Advogado. ORCID: http://orcid.org/0000-0003-0180-4871 / e-mail: romeuprof@ hotmail.com

2 Pós-doutor pela Università Degli Studi di Messina, Itália. Doutor e Mestre em Direito pela UFMG. Professor dos cursos de Graduação, Mestrado e Doutorado da ESDHC. Promotor de Justiça em Belo Horizonte/MG. ORCID: https://orcid.org/0000-0002-0065-1925 / e-mail: lgribeirobh@gmail.com 


\section{THE DECOMMISSIONING OF DAMS AND THE MINE CLOSURE PLAN AS MINING RISK MITIGATION INSTRUMENTS}

\section{ABSTRACT}

Mining modifies the environment and produces socioenvironmental risks, clearly seen from the occurrence of disasters that marked the trajectory of mineral exploration in Brazil. The objective of this paper is to analyze, from the perspective of the principles of prevention and the polluter pays, the effectiveness of the norms that prohibited the use of the so-called upstream dam method and determined the decommissioning of tailings dams, in addition to those that determine mine closure and repair of the area degraded by mining. The research was based on primary and secondary data consisting of analysis of legislative texts and doctrine. It was possible to conclude that the public power should encourage the implementation of the internalisation of negative externalities by mining enterprises, requiring the adoption of preventive measures.

Keywords: dams; internalization; mining; negative externalismos; risks. 


\section{INTRODUÇÃO}

Os desastres socioambientais ocorridos em Bento Rodrigues e em Brumadinho nos anos de 2015 e 2019, respectivamente, ambos decorrentes do rompimento de barragens de rejeito da mineração, evidenciaram a necessidade da adoção, tanto pelo poder público quanto pela iniciativa privada, de medidas eficazes destinadas ao encerramento planejado da atividade minerária, sob a luz dos princípios do desenvolvimento sustentável, da prevenção e do poluidor-pagador.

Barragens de rejeito, ativas ou desativadas, podem representar uma grande ameaça à vida humana e ao meio ambiente caso não sejam adequadamente monitoradas e descaracterizadas. Minas abandonadas, por sua vez, representam um passivo ambiental que a sociedade não está disposta a suportar.

Nesse contexto, o presente trabalho apresenta como problema de pesquisa a seguinte indagação: as respostas normativas oferecidas pelo poder público aos referidos passivos socioambientais são instrumentos jurídicos eficazes para internalizar as externalidades negativas decorrentes da mineração, mitigando, assim, os riscos da atividade?

O objetivo do trabalho é, portanto, analisar, sob a perspectiva dos princípios da prevenção e do poluidor-pagador, a eficácia das normas que vedaram a utilização do método de alteamento de barragens denominado a montante e determinaram a descaracterização de barragens de rejeitos da mineração, além daquelas que preveem o adequado fechamento de mina e a recuperação da área degradada pela mineração.

Trata-se de pesquisa que se valeu de dados primários e secundários consistentes na análise de textos legislativos e doutrina, além do raciocínio dedutivo capaz de sustentar a síntese de que as respostas normativas oferecidas pelo poder público, mais especificamente aquelas relacionadas à proibição de alteamento a montante e à exigência de descaracterização de barragens de rejeito, contribuem para a redução dos riscos e da vulnerabilidade da atividade minerária.

A escassez bibliográfica em relação aos instrumentos jurídicos necessários para a mitigação dos riscos da mineração a partir da internalização das externalidades negativas justifica a escolha do tema proposto. 


\section{A MITIGAÇÃO DE RISCOS DECORRENTES DA MINERAÇÃO A PARTIR DA INTERNALIZAÇÃO DAS EXTERNALIDADES NEGATIVAS}

É cediço que a exploração mineral foi responsável pela ocupação do nosso território e tem sido essencial para o crescimento econômico do Brasil. Desde o período colonial, com a extração de ouro e de diamante, passando pelo Império e pela República, com a produção de minério de ferro, a atividade consolidou-se como um dos sustentáculos da economia nacional.

A pujança econômica do setor mineral brasileiro contrasta, todavia, com os impactos negativos e os danos decorrentes da exploração mineral. Trata-se de atividade que tem como características intrínsecas a modificação do meio ambiente e a geração de riscos socioambientais, visualizados nitidamente a partir da ocorrência de desastres que marcaram negativamente a trajetória da exploração mineral no Brasil.

Rompimentos de barragens de rejeito, como as de Mariana em 2015 e de Brumadinho em 2019, ambas no Estado de Minas Gerais, são inadmissíveis, sobretudo por decorrerem de falhas no gerenciamento dos riscos, nas práticas de segurança, no planejamento estratégico e da tímida inovação tecnológica. Não remanescem dúvidas de que os empreendimentos minerários devem passar a considerar seriamente e de forma mais abrangente os riscos decorrentes da sua atividade com o intuito de evitar ou, ao menos, minimizar, os efeitos negativos da atividade sobre o meio ambiente e a sociedade.

Observam Leite e Canotilho (2007) que vivemos um estágio da modernidade na qual começam a tomar corpo as ameaças produzidas até então pelo modelo econômico da sociedade industrial. Para Ulrich Beck (2010), o que caracteriza a modernidade atual é a produção social de riscos, que sistematicamente acompanha a produção de riquezas. A busca constante pelo crescimento econômico apresenta, como consequência, o desencadeamento de riscos, potencializando autoameaças numa medida até então desconhecida pelo ser humano.

É imperioso reconhecer que os riscos produzidos pelas atividades antrópicas precisam passar a ser considerados, em todas as suas etapas de produção, pelas fontes utilizadoras de recursos naturais. Nesse sentido, Beck (2010) afirma que uma das vertentes para a análise da dinâmica política dos potenciais de autoameaça civilizatória verificados atualmente é 
exatamente o combate às "causas" no processo de industrialização. Não se pode olvidar que os riscos podem apresentar efeitos colaterais não apenas ao meio ambiente, mas também efeitos sociais, econômicos e políticos (THOMÉ, 2014) e, por isso, devem ser combatidos na sua origem. Nesse mesmo sentido, Délton Winter de Carvalho (2019, p. 13) destaca que o direito dos desastres "está intimamente relacionado com a gestão do risco. Em face da magnitude desses eventos, a máxima 'é melhor prevenir do que remediar' trata-se do elemento nuclear desse ramo jurídico".

Corroboram esse entendimento Engelmann, Berwig e Wittckind (2017, p. 295) ao afirmarem que

A sociedade moderna experimenta uma exposição aos riscos tecnológicos sem precedentes, riscos estes que se concretizaram em desastres com alto poder de destruição. Bhopal (1984), Chernobyl (1986), Golfo do México (2010), Fukushima (2011) e Mariana (2015) são os mais conhecidos mundialmente. Todos estes eventos são decorrentes dos modelos econômicos de produção dinâmica que, conectados pela globalização, oportunizaram o desenvolvimento ágil. Por outro lado, a deficiência na gestão dos riscos implicados resulta em sérios danos humanos e ambientais que se pulverizam no espaço e se perpetuam no tempo.

Os riscos da sociedade atual não se limitam aos impactos negativos já verificados. Há um componente futuro a ser levado em consideração. Ensina Beck (2010, p. 39) que "riscos têm [...] fundamentalmente que ver com antecipação, com destruições que ainda não ocorreram, mas que são iminentes, e que, justamente nesse sentido, já são reais hoje". São exatamente esses riscos futuros iminentes que precisam ser evitados e, para tanto, há inúmeros instrumentos, inclusive jurídicos, que devem ser utilizados (THOMÉ, 2014).

Tais singularidades demonstram que os riscos devem ser considerados efeitos reais das atividades industriais, que causam e poderão causar graves danos ao meio ambiente e à saúde humana. É preciso abandonar a concepção de risco adotada nos dias atuais (THOMÉ, 2014). O termo risco não pode comportar a acepção de algo inexistente simplesmente por ser, muitas vezes, incerto ou imperceptível.

Para combater os riscos socioambientais em sua origem, é essencial, entre outras estratégias, que o empreendimento internalize, no seu próprio custo de produção, as externalidades negativas decorrentes da atividade produtiva, nos termos do que preconiza o princípio do poluidor-pagador.

Em outras palavras, os custos resultantes da exploração dos recursos naturais devem ser assumidos pelo próprio empreendimento. Isso significa 
dizer que a atividade deve arcar com os custos necessários à eliminação, neutralização ou diminuição do risco de dano ambiental.

Ao fomentar a internalização das externalidades socioambientais negativas, o princípio do poluidor-pagador objetiva imputar ao poluidor (ou potencial poluidor) o custo social da poluição por ele gerada (ou que possa ser por ele gerada). Sempre que os custos sociais externos (de prevenção, reparação e/ou repressão) que acompanham os processos produtivos (externalidades negativas) não são suportados pelos próprios agentes econômicos, eles são arcados pela coletividade (socialização de perdas).

Ensina Derani (2008, p. 142), ao abordar o princípio do poluidor-pagador, que

[...] durante o processo produtivo, além do produto a ser comercializado, são produzidas 'externalidades negativas'. São chamadas externalidades porque, embora resultantes da produção, são recebidas pela coletividade, ao contrário do lucro, que é percebido pelo produtor privado. Daí a expressão 'privatização de lucros e socialização de perdas', quando identificadas as externalidades negativas. Com a aplicação deste princípio procura-se corrigir este custo adicionado à sociedade, impondo-se sua internalização.

Quando uma empresa mineradora, que durante anos auferiu lucros significativos com a exploração mineral, abandona uma barragem de rejeitos relegando um passivo ambiental à coletividade, verifica-se a existência de uma externalidade negativa decorrente da atividade minerária, pois restam transferidos os impactos negativos da atividade à sociedade, que deverá, então, suportá-los. Nesse caso, constata-se nitidamente a privatização dos bônus (lucros) e a socialização dos ônus (passivos socioambientais).

Nessa esteira, observa Carneiro (2001, p. 72) que externalidades efeitos externos negativos ou deseconomias externas - "correspondem a custos econômicos que circulam externamente ao mercado e, portanto, não são compensados pecuniariamente, mas transferidos sem preço, e suportados pela coletividade". Para Nusdeo (2006, p. 359), as “externalidades podem ser definidas como custos ou benefícios que se transferem de determinadas unidades do sistema econômico para outras, ou para a comunidade como um todo, fora do mercado".

É inegável que os impactos socioambientais são alguns dos principais efeitos externos negativos da produção mineral. Para corrigir as externalidades negativas da mineração, a sociedade normalmente se apoia na atuação de um agente externo ao mercado, o Estado, que responde por 
meio da formulação de políticas públicas "tendentes a convencer os agentes econômicos a considerar os custos sociais da degradação ambiental em seus cálculos privados" (CARNEIRO, 2001, p. 73). As políticas públicas podem ser implementadas por meio de mecanismos como a regulação direta do comportamento dos agentes econômicos e a adoção de incentivos e instrumentos de natureza econômica que induzam o poluidor a não degradar a natureza (THOMÉ, 2019).

Interessa analisar, no presente trabalho, sob o viés de uma concepção econômica do direito, as respostas regulatórias estatais apresentadas pós Mariana (2015) e Brumadinho (2019) direcionadas à eliminação ou à diminuição dos riscos decorrentes da exploração mineral. Como ensina Sarat (2009), uma das dimensões em que o Direito deve lidar em casos de desastres é a da redução da vulnerabilidade futura. Cabe analisar, portanto, como o poder público, a partir da elaboração de normas jurídicas, passou a fomentar a internalização das externalidades negativas pelos empreendimentos minerários, exigindo a adoção de medidas preventivas, especialmente no que tange à recuperação das áreas degradadas e à mitigação dos riscos inerentes às barragens de rejeito.

\section{FECHAMENTO DE MINA E RECUPERAÇÃO DA ÁREA DEGRADADA}

A esgotabilidade da jazida mineral e a geração de impactos socioambientais negativos são características da atividade minerária que fundamentam a necessidade de planejamento para o fechamento de mina e a recuperação da área degradada.

Os bens minerais são recursos naturais não renováveis, o que significa dizer que não podem ser refeitos ou regenerados pelo ser humano ou pela natureza. São elementos encontrados na natureza em forma de reservas ou jazidas que, incontestavelmente, são finitas.

Trata-se, ainda, de atividade impactante do meio ambiente. Os impactos negativos da exploração dos recursos minerais estão relacionados à alteração da topografia, à movimentação de terra, à poluição das águas, ao afugentamento de espécies animais, entre outros.

Ao iniciar a exploração de uma jazida mineral o empreendedor tem, portanto, ao menos duas certezas: de que a mina alcançará sua exaustão e de que a atividade causará impactos negativos sobre o meio ambiente. Tais constatações são suficientes para que sejam exigidas do empreendimento, 
desde as primeiras etapas do licenciamento ambiental, medidas direcionadas ao adequado fechamento da mina e à recuperação da área impactada. Com a chegada ao fim da vida útil da jazida mineral, é preciso que já se saiba o que fazer com as instalações utilizadas e como reverter os impactos socioambientais negativos decorrentes da sua exploração.

A relevância de um planejamento antecipado do fechamento de mina foi reconhecida internacionalmente durante a $5^{\text {a }}$ Conferência dos Ministérios de Minas das Américas (CAMMA), realizada em 1999 em Vancouver, no Canadá (ARAUJO, 2015). Ficou acordado que

[...] as etapas de desativação e fechamento dos projetos minerais deve ser considerada desde o início do desenvolvimento do projeto, constituindo o plano de desativação planificado um elemento necessário para que a mineração contribua para o desenvolvimento sustentável, facilitando assim a existência de condições claras e estáveis para alcançar o bem-estar econômico, ambiental e social (SOUZA, 2003).

O termo fechamento de mina designa a cessação definitiva das operações mineiras, fase final da atividade minerária. De uma maneira geral, pode-se considerar o fechamento de mina como um processo de encerramento das atividades de lavra por razões de ordem técnica, legal ou econômica, em virtude de esgotamento ou exaustão da reserva mineral ou em razão da inexistência de condições que permitam a continuidade da lavra de um depósito mineral (REIS; BARRETO, 2001).

$\mathrm{Na}$ etapa do fechamento não há extração do minério, em decorrência da exaustão da jazida ou da inviabilidade técnico-econômica da atividade. Nessa fase desenvolvem-se ações e procedimentos direcionados à estabilização física, química e biológica da área impactada, à recuperação do meio ambiente degradado e ao reequilíbrio socioeconômico local e regional no entorno do empreendimento.

Importante ressaltar que apenas recentemente o fechamento de mina passou a ser considerado como uma das fases do empreendimento minerário. Não são raros os casos de minas abandonadas em diversos países do mundo. "Na província de Ontário, no Canadá, seriam mais de 6 mil minas abandonadas (MITCHELL; MACKASEY, 1995 apud SÁNCHEZ, 2001), no estado de Queensland, na Austrália, são cerca de 50 mil”, relata Araujo (2015, p. 8). No Missouri [EUA], acredita-se que há cerca de 8 mil minas abandonas. Já em Montana e no Colorado, vinte mil, e no Arizona, oitenta mil (DURKING; HERRMANN, 1996 apud SÁNCHEZ, 2001). O Serviço Nacional de Geologia e Mineração do Chile, por sua vez, detectou mais de 520 (quinhentos e vinte) cavas abandonadas na Cordilheira dos 
Andes, responsáveis pela contaminação da água, do solo e do ar. Os maiores impactos ambientais estão localizados nas regiões de Atacama, Coquimbo, Antofagasta, Metropolitana e Valparaíso (ARAUJO, 2015).

No Brasil, destaca-se o caso da Mina de Engenho D'Água, da Mundo Mineração, que interrompeu suas atividades no município de Rio Acima/ MG há alguns anos, deixando no local apenas placas indicativas da presença de material tóxico, como arsênico e mercúrio, utilizado na extração de ouro (MG TEM..., 2019). Observa Araujo (2015, p. 9) que

\footnotetext{
Casos particularmente preocupantes são as minas abandonadas de carvão e metais, pois podem gerar Drenagem Ácida de Minas (DAM), caracterizada pela oxidação de minerais de sulfeto, que provoca degradação da qualidade de águas superficiais e subterrâneas, solos e sedimentos.
}

Araujo (2015) destaca como emblemático, no âmbito internacional, o caso da mina de ouro Zortman-Landusky, no estado de Montana, nos Estados Unidos, que foi abandonada pela empresa Pegasus, em 1998, deixando um passivo ambiental de noventa milhões de dólares.

Inúmeras minas foram abandonadas nas últimas décadas sem que seus impactos fossem avaliados pelo poder público e pela sociedade brasileira. De acordo com dados apresentados pela Fundação Estadual do Meio Ambiente de Minas Gerais (FEAM) no ano de 2016, foram detectadas 400 (quatrocentas) minas abandonadas ou desativadas somente no Estado de Minas Gerais (MG TEM..., 2019), representando um significativo passivo socioambiental.

Com o intuito de evitar que situações semelhantes se repitam, as normas ambientais nacionais passaram a exigir que o empreendimento apresente ao poder público as medidas a serem adotadas tanto para evitar ou minimizar os impactos socioambientais da fase final da exploração mineral, quanto para a recuperação da área degradada pelo empreendimento.

A exigência de recuperação da área degradada pela mineração tem esteio no artigo 225 , parágrafo $2^{\circ}$ da Constituição de 1988 , posteriormente regulamentado por normas infraconstitucionais, tais como o Decreto $\mathrm{n}$. 97.632, de 10 de abril de 1989, que, a partir da determinação prevista no artigo $2^{\circ}$, inciso VIII, da Lei n. 6.938/81 (Lei de Política Nacional do Meio Ambiente), tornou obrigatória a apresentação, por todos os empreendimentos minerários, de Plano de Recuperação das Áreas Degradadas (PRAD), simultaneamente à entrega dos Estudos e Relatórios de Impacto Ambiental (EIA/RIMA). 
O PRAD deve, portanto, prever as ações destinadas ao "retorno do sítio degradado a uma forma de utilização, de acordo com um plano preestabelecido para o uso do solo, visando à obtenção de uma estabilidade do meio ambiente" (art. $3^{\circ}$ do Decreto n. 97.632/89).

Impõe-se reconhecer, no entanto, que foram normas administrativas editadas pelo antigo Departamento Nacional de Produção Mineral $(\mathrm{DNPM})^{3}$ que pela primeira vez mencionaram de maneira explícita a fase de fechamento de mina. As Normas Reguladoras de Mineração (NRM), publicadas no Diário Oficial da União em 18 de outubro de 2001 (Portaria 237), preveem a obrigatoriedade de apresentação, ao órgão competente, de um Plano de Fechamento, Suspensão e Retomada das Operações Minerais, como requisito para a concessão de lavra (item 1.5.1, i). O referido plano deve ser objeto de revisões periódicas ao longo da vida do empreendimento (item 20.4.2.1), bem como deve integrar o Plano de Aproveitamento Econômico (item 1.5.7), outro documento de apresentação indispensável pelo empreendimento (BRASIL, 2001).

A exigência de apresentação de Plano de Fechamento de Mina (PFM) juntamente com o Plano de Aproveitamento Econômico (PAE) como requisito para a obtenção da concessão de lavra foi confirmada com a edição do Decreto n. 9.406, de 12 de junho de 2018, que regulamenta a atividade minerária em todo o território nacional.

Art. 32. O plano de aproveitamento econômico, firmado por profissional legalmente habilitado, é documento obrigatório do requerimento de concessão de lavra e deverá conter, além dos documentos e das informações exigidas pelo art. 39 do Decreto-Lei n. 227, de 1967 - Código de Mineração, descrição das instalações de beneficiamento, indicadores relativos às reservas e produção e plano de fechamento da mina, nos termos estabelecidos em Resolução da ANM (BRASIL, 2018).

Importante ressaltar que o PRAD previsto no Decreto n. 97.632/89 não se confunde com o PFM regulamentado pela legislação mineral federal. O Decreto n. 9.406/2018, que regulamentou o Código de Mineração (Decreto-Lei n. 227/1967), estabelece que o empreendedor deve apresentar à Agência Nacional de Mineração (ANM), como um dos requisitos para o requerimento de concessão de lavra, o Plano de Aproveitamento Econômico (PAE), que é composto, entre outros documentos, pelo Plano de Fechamento de Mina (PFM), (art. 32 do Decreto n. 9.406/2018). Assim, o PFM exigido pelo Código de Mineração é um requisito de ordem econômica (para a concessão de lavra), enquanto o Plano de Recuperação

3 Substituído pela Agência Nacional de Mineração (ANM). 
da Área Degradada (PRAD) exigido pelo Decreto n. 97.632/89 é um requisito de ordem ambiental (para fins de licenciamento ambiental) e deve ser apresentado ao órgão ambiental licenciador competente. São documentos que, apesar de direcionados a órgãos públicos distintos, assemelham-se por apresentam ações que visam à estabilização física, química e biológica da área impactada, à recuperação do meio ambiente degradado e ao reequilíbrio socioeconômico local e regional no entorno do empreendimento.

Convém, nesse ponto, registrar que o Brasil segue a trilha de alguns países mineradores que já inseriram em suas normas ações destinadas à adequação da etapa de fechamento de mina aos preceitos do Direito Ambiental.

No Chile, a Lei n. 20.511/2011 estabelece que todas as operações de mineração devem ter um plano de encerramento de mina aprovado antes do início das operações. Na Alemanha, as Diretrizes de Berlim, de 1994, regulam a mineração e o fechamento de mina. $\mathrm{O}$ documento conta com uma seção sobre planejamento de fechamento de mina e reabilitação, dividido em três etapas: (a) fase de planejamento; (b) fase de cuidado ativo, relacionada com o processo de encerramento, e (c) fase de cuidados passivos, relacionada com a monitoração do local da mina (HOSKIN, 2005, apud SCALON, 2014). Já no Canadá, na província de Ontário, as diretrizes para fechamento de minas preveem requisitos que têm como intuito estabilizar a área minerada por, no mínimo, 200 anos (DORAM; McINTOSH, 1995 apud SÁNCHEZ, 2001; (ARAUJO, 2015).

O fechamento de uma mina envolve, portanto, uma série de medidas voltadas ao descomissionamento do empreendimento e à recuperação socioambiental da área impactada pela atividade. Descomissionar uma mina significa desativá-la, além de desmantelar sua estrutura, "repartindo-a" em estruturas menores. As ações de descomissionamento, complementa Taveira (2003), destinam-se a efetuar a transição entre o fechamento e o uso futuro da área.

Vale reforçar que o adequado fechamento de mina e a recuperação da área degradada são ações de responsabilidade do empreendimento minerário, que deve, desde as fases iniciais de exploração mineral, prever os valores a serem despendidos para sua implementação em seu orçamento, internalizando, assim, no seu próprio custo de produção, as externalidades negativas decorrentes da sua atividade. Ao executar essas ações, a 
atividade reduz a vulnerabilidade futura e diminui, significativamente, a probabilidade de ocorrência de danos socioambientais.

Ensinam Pérez e Peña (2014) que "uma mina consiste em um conjunto de instalações que têm um tempo de vida variável, dependendo da natureza e das características dos processos de produção. Ela pode contar com várias zonas produtivas e diversas atividades dentro de sua área geográfica”. Uma das estruturas de uma mina que demanda descomissionamento, incluindo a sua descaracterização, em virtude dos comprovados riscos impostos à sociedade, são as barragens de rejeito da mineração, que merecem, portanto, uma análise mais detalhada.

\section{DESCARACTERIZAÇÃO DE BARRAGENS DE REJEITO DA MINERAÇÃO}

As barragens foram idealizadas há centenas de anos e com o intuito inicial de controle do fluxo hídrico. Com a Revolução Industrial e o aumento da demanda energética, elas passaram a ser utilizadas também para a produção de energia hidrelétrica. A partir de então, essas enormes estruturas são utilizadas para diversas atividades e objetivos, como para a retenção de resíduos industriais e de outros processos produtivos. De acordo com Toledo, Ribeiro e Thomé (2016, p. 15),

Estas barragens representam, então, uma categoria especializada desse tipo de estrutura de contenção de material, dotada de porte distinto e funcionamento próprio em comparação com as barragens hidrelétricas e de controle de fluxo hídrico. Nesse contexto, barragem pode ser conceituada como qualquer estrutura em um curso permanente ou temporário de água para fins de contenção ou acumulação de substâncias líquidas ou de misturas de líquidos e sólidos, compreendendo o barramento e as estruturas associadas (art. $2^{\circ}$, I da Lei n. 12.334/2010).

A atividade minerária vale-se da praticidade das barragens para a contenção dos rejeitos decorrentes da lavra das jazidas minerais. O método mais comum de disposição dos rejeitos da mineração é o seu lançamento em lagos de decantação (aterros hidráulicos), que são represados por barragens (PASSINI; THOMÉ, 2018). Em virtude do aumento na geração de resíduos, impulsionado pela demanda mundial de produtos minerais, as dimensões dessas estruturas vêm sendo ampliadas nas últimas décadas. Para Soares (2010), melhorias técnicas associadas a maiores exigências ambientais têm como resultado o aproveitamento de minérios de baixo 
teor, o que aumenta a quantidade de rejeitos produzida em relação à massa de alimentação da usina.

Convém consignar, por oportuno, que a disposição de rejeitos da mineração em barragens tem se apresentado, sobretudo nas últimas décadas, ambiental e socialmente inadequada. Os riscos inerentes a essas estruturas de contenção foram confirmados por inúmeros rompimentos de barragens, tais como o da barragem de Bafokeng, na África do Sul, em 1974; da mina de Arcturus, no Zimbábue, em 1978 e de uma mina em Trento, na Itália, no ano de 1985. Já nos anos 2000 pode-se citar o rompimento da barragem da usina de carvão de Kingston, nos Estados Unidos, em 2008; da mina de Talvivaara, na Finlândia, em 2012; da mina de Obed Moutains, em 2013, no Canadá, onde houve também o rompimento da barragem da mina de Mount Polley, no ano de 2014.

Em solo brasileiro, especialmente em Minas Gerais, ente detentor de inegável vocação mineira, uma série de rompimentos de barragens foi responsável por perdas humanas e danos ambientais incomensuráveis. O rompimento da barragem da mina de Fernandinho, em 1986, na cidade de Itabirito/MG, inaugura essa lamentável sequência. Em 2001, em Sebastião das Águas Claras/MG, o rompimento de outra barragem matou cinco operários, assoreou 6,4 quilômetros do leito do córrego Taquaras e atingiu 43 hectares de vegetação. Já em 2007, em Miraí, região da Zona da Mata mineira, quatro mil moradores e mil e duzentas casas foram atingidas pela ruptura da barragem de empreendimento minerário. Operários mineiros foram soterrados, em 2014, quando realizavam a manutenção no talude de uma barragem de rejeitos desativada localizada no Estado de Minas Gerais (TOLEDO; RIBEIRO; THOMÉ, 2016).

Em razão da magnitude e da abrangência, duas tragédias marcaram negativa e definitivamente a história da mineração brasileira: a de Bento Rodrigues/MG, em 2015, e a de Brumadinho, em 2019. No dia 5 de novembro de 2015, "a lama proveniente da ruptura da barragem do Fundão invadiu Bento Rodrigues, distrito da cidade histórica de Mariana (Minas Gerais), deixando dezenove mortos, dezenas de famílias desabrigadas, e causando um incalculável impacto negativo sobre o meio ambiente da região" (TOLEDO; RIBEIRO; THOMÉ, 2016, p. 66). Imaginava-se tratar do maior desastre ambiental da história do Brasil. Nada disso. Apenas três anos e dois meses depois, no dia 25 de janeiro de 2019, a barragem do Córrego do Feijão, em Brumadinho/MG, cedeu e o mar de lama dali originado suprimiu a vida de ao menos duzentas e quarenta e quatro 
pessoas (NÚMERO DE VÍTIMAS..., 2019) e causou uma das maiores tragédias ambientais da história mundial.

Esses marcantes acontecimentos tornaram inadiável, portanto, a adoção de novos métodos de exploração mineral e de técnicas mais seguras de disposição final de rejeitos da mineração, social e ambientalmente mais adequados.

As primeiras respostas normativas aos rompimentos de barragem se deram em âmbito estadual, com a publicação do Decreto n. 46.993/2016, posteriormente alterado pelo Decreto n. 47.158/2017, que suspendeu temporariamente, em Minas Gerais, o licenciamento ambiental de novas barragens de rejeitos nas quais se pretendesse utilizar o método de alteamento a montante e o alteamento de estruturas existentes que pretendessem utilizar esse método.

Vale lembrar que o método de alteamento a montante é aquele em que os diversos degraus da barragem são erguidos à medida que a quantidade de rejeitos aumenta, e são construídos contra o barranco ou a parede que dá sustentação à estrutura (GERAQUE, 2015). É considerado o método mais comum e economicamente mais vantajoso para as empresas, e que exige maiores cuidados de manutenção em relação a outros métodos construtivos (LAGO; THOMÉ, 2017).

A Lei n. 23.291/2019, que institui a política de segurança de barragens do Estado de Minas Gerais, passou a vedar expressamente, em seu artigo 13, o licenciamento ambiental para operação ou ampliação de barragens destinadas à acumulação ou à disposição final ou temporária de rejeitos ou resíduos industriais ou de mineração que utilizem o método de alteamento a montante.

Em âmbito nacional, a Resolução n. 4 da Agência Nacional de Mineração - ANM, de 15 de fevereiro de 2019, dispõe no mesmo sentido, proibindo a utilização do método de construção ou alteamento de barragens de mineração denominado a montante em todo o território nacional.

A proibição do alteamento de barragens a montante, método construtivo mais econômico para as empresas e o menos seguro para a população e o meio ambiente, é relevante na medida em que impede que futuros empreendimentos minerários se utilizem dele para a disposição dos rejeitos da atividade. Todavia, não se pode olvidar que inúmeras barragens em atividade já se encontram construídas e alteadas a partir do emprego dessa técnica e que tantas outras estão desativadas ou abandonadas, representando um enorme risco a toda a sociedade. 
Não basta, portanto, proibir o alteamento de novas barragens pelo método à montante. Impõe-se que as barragens já construídas sejam desativadas e descaracterizadas (descomissionadas), eliminando, assim, a possibilidade da ocorrência de novos desastres. Nos termos do artigo 18 da Lei Federal n. 12.334/2010, que estabelece a Política Nacional de Segurança de Barragens, "a barragem que não atender aos requisitos de segurança nos termos da legislação pertinente deverá ser recuperada ou desativada pelo seu empreendedor, que deverá comunicar ao órgão fiscalizador as providências adotadas".

Observa Araújo (2018) que "a maior parte das empresas do setor minerário, enxergava a barragem de rejeitos como um ponto final de sua linha produtiva". Entretanto, nas últimas décadas, a realidade tem demonstrado que a atividade minerária não se encerra com a disposição de rejeitos em barragens. Inúmeras ações devem ser desenvolvidas a partir da contenção dos rejeitos, tais como a recuperação e nova destinação às substâncias dispostas nos rejeitos de mineração, a descaracterização das barragens e a recuperação da área degradada.

Assim como as minas devem obedecer ao planejamento previsto no Plano de Recuperação da Área Degradada (PRAD) e no Plano de Fechamento de Mina (PFM) para o adequado encerramento de suas atividades, as barragens de rejeito devem obedecer à mesma lógica, pois não é admissível que tais estruturas, uma vez desativadas, permaneçam encravadas no solo aguardando que sejam, naturalmente, integradas ao meio ambiente. Até mesmo as barragens ativas, que utilizaram o método à montante para o seu alteamento, devem ser descaracterizadas para que novos rompimentos sejam evitados.

Para Chambers (2015), os estragos causados pela ruptura de barragens da mineração teriam sido muito menores se os resíduos das minas fossem menos fluídos. Tal constatação atesta a necessidade de desativação e descaracterização das barragens de rejeito (aterros hidráulicos), especialmente aquelas alteadas a partir do método a montante.

Após o rompimento da barragem do Córrego do Fundão, em Brumadinho, no ano de 2019, observou-se uma reação legislativa, ainda que tardia, no sentido da determinação da descaracterização das barragens de rejeito que utilizam o método a montante de alteamento.

Nos termos do parágrafo $1^{\circ}$ do artigo 13 da Lei n. 23.291, de 25 de fevereiro de 2019, no Estado de Minas Gerais, o empreendedor fica "obrigado a promover a descaracterização das barragens inativas de 
contenção de rejeitos ou resíduos que utilizem ou que tenham utilizado o método de alteamento a montante".

Nos casos de barragens ainda em operação, determina o referido instrumento normativo estadual que o empreendedor deverá promover a migração para tecnologia alternativa de acumulação ou disposição de rejeitos e resíduos e a descaracterização da barragem, no prazo de até três anos contados a partir da publicação da lei.

Resta claro o objetivo da norma estadual no sentido de implementar a internalização das externalidades negativas ao determinar, aos empreendimentos minerários, que arquem com os custos necessários para a substituição de tecnologia ou para a descaracterização das barragens de rejeito. A obtenção de lucro (privatização dos bônus) pela atividade minerária é legítima, assim como é legítimo que a sociedade exija dos empreendimentos minerários que sejam eles os responsáveis por eliminar os riscos, assumindo os custos de prevenção.

Caso esses custos sociais externos (de prevenção) que acompanham os processos produtivos não sejam assumidos pelos próprios agentes econômicos, eles acabarão sendo suportados pela coletividade. Esse é o caso, supracitado, da mina de Engenho D'Água, em Rio Acima/MG, abandonada pela empresa australiana Mundo Mineração, que deixou para a sociedade mineira passivos ambientais significativos, entre eles, duas barragens com potencial de inutilizar a captação de água responsável pelo abastecimento de 50\% da região metropolitana de Belo Horizonte/MG. Os custos com o tratamento das barragens, que estão sendo, desde 2017, suportados pelo Estado (com os recursos do contribuinte), é significativo: em torno de $\mathrm{R} \$ 15.000 .000,00$ (quinze milhões de reais), sendo $\mathrm{R} \$$ $8.000 .000,00$ (oito milhões de reais) destinados ao tratamento da água das barragens, R\$ 600.000,00 (seiscentos mil reais) empregados no projeto executivo e R \$ 7.300.000,00 (sete milhões e trezentos mil reais) aplicados na obra, além dos gastos com estudos e monitoramento das estruturas (PARREIRAS, 2019).

Para que situações como as das barragens da mina de Engenho D'Água não se repitam, tanto as barragens inativas quanto aquelas em operação, que utilizaram ou utilizam o método de alteamento à montante, deverão se submeter a um procedimento de descaracterização, ou seja, não poderão operar como estrutura de contenção de sedimentos ou rejeitos, uma vez que se impõe a supressão da característica de barragem. Tais estruturas deverão, portanto, ser desativadas ou destinadas a finalidade diversa, as 
expensas do próprio empreendedor (artigo 13, $\S 3^{\circ}$ da Lei n. 23.291/2019). Segundo a Secretaria Estadual do Meio Ambiente e Desenvolvimento Sustentável de Minas Gerais (SEMAD), há no estado, distribuídas em dezesseis cidades mineiras, quarenta e nove barragens alteadas pelo método a montante, sendo vinte e sete delas em operação e vinte e duas paralisadas (RESOLUÇÃO OBRIGA..., 2019).

A empresa Vale, por exemplo, informou, em 08 de junho de 2019, a intensificação das atividades de descaracterização de nove barragens de minério de ferro, alteadas pelo método a montante. A intenção é que duas barragens sejam completamente descomissionadas em três anos, sendo que em outras cinco será promovida a migração para o método a jusante antes de realizada a descaracterização. Afirmou, ainda, a empresa que o fator de segurança será aumentado em outras duas barragens antes da realização das obras de descaracterização (VALE ANUNCIA..., 2019).

Percebe-se, portanto, que as reações normativas do poder público, ao proibir alteamentos a montante e ao determinar a descaracterização de barragens de rejeito da mineração, foram adequadas sob o ponto de vista tanto do princípio da prevenção quanto do princípio do poluidor-pagador, norteadores das normas de direito ambiental.

Em observância ao princípio da prevenção, as normas analisadas determinaram a adoção de medidas com o intuito de mitigar os riscos que envolvem o rompimento de barragens, aumentando a margem de segurança e, consequentemente, diminuindo a probabilidade de que futuros desastres se repitam. Para Carvalho (2019, p. 14),

[...] a Política Nacional de Segurança de Barragens atribui uma grande ênfase ao princípio da prevenção (riscos conhecidos e previsíveis), sem que isso necessariamente exclua a avaliação de riscos incertos ou não quantificáveis (conforme prevê a própria Lei de Política Nacional de Proteção e Defesa Civil, 12.608/2012). O que resta evidente é que os riscos previsíveis devem necessariamente ser enfrentados de forma efetiva e mediante medidas razoáveis para evitar a concretização de danos catastróficos. Os riscos enfrentados no presente caso parecem tratar-se claramente de riscos quantificáveis (ou previsíveis ao estado da arte). No entanto, mesmo riscos não quantificáveis e dotados de incerteza, quando apresentam potencial catastrófico ou de irreversibilidade, exigem decisões construídas sobre uma "adequada margem de segurança". Isso deve ocorrer mesmo em casos em que a probabilidade é muito remota ou não pode ser demonstrada de forma quantificável.

Vale rememorar que os desastres antropogênicos (causados pela ação humana) podem, a partir do adequado gerenciamento de riscos, ser evitados, diferentemente dos desastres naturais que, como observam Engelmann, Berwig e Wittckind (2017, p. 295), "não permitem um controle no início do 
evento, mas somente as consequências destes (respostas de emergências, mitigação e reparação)".

Sob o enfoque do princípio do poluidor-pagador, também se demonstram adequadas as normas publicadas após os desastres de Mariana e Brumadinho, ao exigirem do empreendimento minerário a adoção, às suas expensas, de medidas direcionadas à prevenção de danos e à recuperação do meio ambiente degradado. Internalizam-se assim, nos próprios custos de produção da atividade, as externalidades negativas, evitando-se a produção de passivos ambientais que acabariam sendo suportados por toda a coletividade.

Com o intuito de reforçar ainda mais as garantias financeiras direcionadas à internalização das externalidades negativas decorrentes das atividades minerárias, a Lei n. 23.291/2019 insere, como requisito para a obtenção de Licença Prévia para novas barragens no Estado de Minas Gerais, a previsão de caução ambiental a ser oferecida pelo empreendedor e, para a obtenção da Licença de Operação, a comprovação da efetiva implementação dessa garantia. Os valores apresentados a título de caução têm como intuito assegurar tanto a recuperação socioambiental em casos de dano ambiental quanto a desativação de barragens de rejeitos.

As garantias econômicas apresentam-se como relevantes instrumentos, previsto no ordenamento jurídico de diversos países, direcionado à eliminação do passivo ambiental da atividade minerária. Observa Araujo (2015, p. 11) que,

Para estimular esforços de reabilitação durante a fase operacional da mina e a efetiva implementação do plano de fechamento de mina, a maior parte dos sistemas regulatórios mundiais exigem que as empresas mineradoras apresentem alguma garantia financeira para cobrir despesas das fases de fechamento e de pós-fechamento (ROBERTS, VEIGA, PEITER, 2000; SÁNCHEZ; SILVA-SÁNCHEZ; NERI, 2013). No caso dos Estados Unidos e do Canadá, a regulamentação do mercado de capitais também impõe a necessidade de que as empresas mineradoras façam provisões contábeis para recuperação de áreas degradadas e fechamento de minas (SÁNCHEZ, 2007).

Caução, seguro ambiental e outras garantias econômicas cumprem um importante papel complementar no sentido da internalização das externalidades negativas da mineração, além de funcionarem, ao menos indiretamente, como indutores da adoção de ações preventivas, na medida em que os empreendimentos tendem a adotar todas as medidas necessárias para mitigar os riscos da atividade a partir do momento em que destinaram valores significativos para a reparação, em caso de dano socioambiental. 


\section{CONCLUSÃO}

Os desastres com barragens de rejeitos em Mariana/MG, em 2015, e em Brumadinho/MG, em 2019, explicitaram a necessidade da adoção de práticas mais seguras e sustentáveis na mineração.

O gerenciamento inadequado dos riscos inerentes a cada uma das etapas da atividade pode acarretar passivos socioambientais de magnitudes diversas. No presente trabalho foram analisados impactos negativos detectados, geralmente, na última etapa atividade minerária, comumente denominado fechamento de mina. Tais impactos guardam relação com a gestão deficiente do encerramento da atividade e das ações de descomissionamento das estruturas utilizadas durante a exploração mineral, como as barragens de rejeito.

Minas abandonadas sem qualquer planejamento de fechamento geram diversos passivos ambientais para a sociedade, tais como contaminação de águas superficiais e subterrâneas por drenagem ácida, inutilização da área impactada, cavas instáveis, além do afundamento do solo no caso de minas subterrâneas.

Já as barragens de rejeito, ativas ou abandonadas, representam significativos riscos de dano socioambiental. A utilização, durante décadas, do método de alteamento a montante de barragens, técnica de contenção de rejeitos comprovadamente mais vulnerável, comprova a existência de falhas no gerenciamento dos riscos dessas estruturas.

Para a redução dos riscos e, consequentemente, da vulnerabilidade da atividade minerária, as normas jurídicas apresentam-se como relevante instrumento de implementação de políticas públicas sustentáveis. Evitar que novos passivos socioambientais sejam produzidos é, portanto, um dos principais objetivos das normas de direito ambiental, alicerçadas no princípio da prevenção.

Outra importante função ínsita às normas jurídicas ambientais é fomentar a internalização das externalidades negativas na mineração. De acordo com uma das acepções do princípio do poluidor-pagador, aquele que utiliza ou pretende utilizar os recursos naturais (poluidor) deve ser incentivado a arcar com o custo social da poluição por ele gerada. Sempre que os custos sociais externos (de prevenção, reparação e/ou repressão) que acompanham os processos produtivos (externalidades negativas) não são suportados pelos próprios agentes econômicos, eles são arcados pela coletividade (socialização de perdas). 
A ideia nuclear que motivou os propósitos do presente trabalho foi cumprida ao se demonstrar que ao poder público, a partir da elaboração de normas jurídicas, pode ser incumbida à implementação da internalização das externalidades negativas pelos empreendimentos minerários, exigindo-se a adoção de medidas preventivas, especialmente no que tange à recuperação das áreas degradadas e à mitigação dos riscos inerentes às barragens de rejeito.

\section{REFERÊNCIAS}

ARAUJO, E. R. Fechamento de minas no Brasil não tem legislação federal especifica e coloca em risco o ambiente e populações locais. Brasília, DF: MCTIC, 2015.

ARAÚJO, W. Descaracterização e descomissionamento de barragens de rejeito. Instituto Minere, 18 out. 2018. Disponível em: <https://institutominere.com. $\mathrm{br} / \mathrm{blog} /$ descaracterizacao-e-descomissionamento-de-barragens-de-rejeitosuma-tendencia-ou-realidade>. Acesso em: 3 jun. 2019.

BECK, U. Sociedade do risco: rumo a uma outra modernidade. São Paulo: 34, 2010.

BRASIL. Departamento Nacional de Produção Mineral. Portaria n. 237, de 18 de outubro de 2001. Aprova as Normas Reguladoras de Mineração NRM, de que trata o Art. 97 do Decreto-Lei n. 227, de 28 de fevereiro de 1967. Brasília, DF: DNPM, 2001. Disponível em: <http://www.dnpm.gov.br/ acesso-a-informacao/legislacao/portarias-do-diretor-geral-do-dnpm/portariasdo-diretor-geral/portaria-no-237-em-18-10-2001-do-diretor-geral-do-dnpm>. Acesso em: 7 nov. 2018.

BRASIL. Decreto n. 9.406, de 12 de junho de 2018. Regulamenta o DecretoLei n. 227, de 28 de fevereiro de 1967, a Lei n. 6.567, de 24 de setembro de 1978, a Lei n. 7.805, de 18 de julho de 1989, e a Lei n. 13.575, de 26 de dezembro de 2017. Disponível em: <http://www.planalto.gov.br/ccivil_03/_ Ato2015-2018/2018/Decreto/D9406.htm>. Acesso em: 17 mai. 2019.

CARNEIRO, R. Direito Ambiental: uma abordagem econômica. Rio de Janeiro: Forense, 2001.

CARVALHO, D. W. Brumadinho, 2019: análise das narrativas de uma catástrofe a partir do direito dos desastres. Revista dos Tribunais, São Paulo, ano 108, v. 1002, p. 87-102, 2019.

CHAMBERS, D. Desastre da Samarco mostra o verdadeiro custo das soluções 
baratas. Redesul, 2015. Disponível em: <https://www.redesul.com.br/noticias/ show/noticia/44088-desastre-da-samarco-mostra-os-verdadeiro-custo-dassolucoes-baratas>. Acesso em: 11 dez. 2015.

DAMACENA, F. D. L. Direito dos desastres e compensação climática no Brasil: limites e potencialidades. Rio de Janeiro: Lumen Juris, 2019.

DERANI, C. Direito Ambiental Econômico. São Paulo: Saraiva. 2008.

ENGELMANN, W.; BERWIG, J. A.; WITTCKIND, E. V. O desastre de Bhopal: riscos e vulnerabilidades na transferência de tecnologias e o direito de saber. Belo Horizonte: Revista Veredas do Direito, v. 14, n. 30, p. 293-316, set./dez. 2017.

GERAQUE, E. Samarco utilizou modelo mais barato e inseguro de barragem. Folha de S.Paulo, 8 dez. 2015. Disponível em: <http://www1.folha.uol.com. br/cotidiano/2015/12/1716184-samarco-utilizou-modelo-mais-barato-einseguro-de-barragem.shtml>. Acesso em: 23 ago. 2015.

LAGO, T.; THOMÉ, R. Barragens de rejeitos da mineração: o princípio da prevenção e a implementação de novas alternativas. Revista de Direito Ambiental, São Paulo, v. 85, p. 17-39, jan./mar. 2017.

LEITE, J. R. M.; CANOTILHO, J. J. G. Direito constitucional ambiental brasileiro. São Paulo: Saraiva, 2007.

MG TEM 400 minas abandonadas ou desativadas. Correio Braziliense, 11 fev. 2019. Disponível em: <https://www.correiobraziliense.com.br/app/noticia/ brasil/2019/02/11/interna-brasil,736713/mg-tem-400-minas-abandonadas-oudesativadas-especialistas-bomba.shtml > . Acesso em: 23 ago. 2019.

NÚMERO DE VÍTIMAS identificadas na tragédia da Vale sobe para 244. G1 Minas, 27 maio 2019. Disponível em: <https://g1.globo.com/mg/minasgerais/noticia/2019/05/27/numero-de-vitimas-identificadas-na-tragedia-davale-sobe-para-244.ghtml>. Acesso em: 29 maio 2019.

NUSDEO, A. M. O. O uso de instrumentos econômicos nas normas de proteção ambiental. Revista da Faculdade de Direito da Universidade de São Paulo, São Paulo, v. 101, p. 357-378, jan./dez. 2006.

PARREIRAS, M. Contribuinte terá que pagar R\$ 15 milhões para descaracterização de barragens em Rio Acima. Estado de Minas, 13 maio 2019. Disponível em: <https://www.em.com.br/app/noticia/gerais/2019/05/13/ interna_gerais, 1053463/contribuinte-tera-que-pagar-r-15-milhoes-paradescaracterizacao-de-ba.shtml>. Acesso em: 10 jun. 2019. 
PASSINI, M. L.; THOMÉ, R. Barragens de rejeitos de mineração: características do método de alteamento para montante que fundamentaram a suspensão de sua utilização em Minas Gerais. Ciências Sociais Aplicadas em Revista - UNIOESTE/MCR, Marechal Cândido Rondon, v. 18, n. 34, p. 49-65, 2018.

PÉREZ, Y. S.; PEÑA, J. M. M. La planificación del cierre de minas como parte de la sustentabilidad em La minería. Observatorio de la Economía Latinoamericana, n. 199, 2014. Disponível em: <http://www.eumed.net/ cursecon/ecolat/cu/2014/minas.html>. Acesso em: 10 out. 2014.

REIS, N. L. BARRETO, M. L. Desativação de empreendimento mineiro no Brasil. São Paulo: Signus, 2001.

RESOLUÇÃO OBRIGA 19 mineradoras a descaracterizar suas barragens. Estado de Minas, 3 fev. 2019. Disponível em: <https://www.em.com.br/ app/noticia/gerais/2019/02/03/interna_gerais,1027440/resolucao-obriga-19mineradoras-a-descaracterizar-suas-barragens.shtml $>$. Acesso em: 17 jun. 2019.

REZENDE, É. N.; FLORIANO NETO, A. Responsabilidade civil ambiental da empresa diante das tragédias ambientais decorrentes do rompimento de barragens: uma análise à luz dos princípios da função social e da preservação da empresa. Revista Húmus, São Luís, v. 9, p. 310-330, 2019.

SÁNCHEZ, L. E. Desengenharia: o passivo ambiental na desativação de empreendimentos industriais. São Paulo: Edusp, 2001.

SARAT, A.; LEZAUN, J. (Eds.). Catastrophe: law, politics, and the humanitarian impulse. Amherst: University of Massachusetts, 2009.

SAMPAIO, J. A. L.; SOUZA, L. M. C. G. Licenciamento ambiental e concessão minerária: perspectivas da Política Nacional de Segurança de Barragem. Nomos, Fortaleza, v. 37, p. 93-115, 2017.

SCALÓN, M. G. B. Have the international guidelines for mine closure been internalized by the Brazilian legal framework? Apresentação feita no Proceedings of Mine Closure Solutions, Ouro Preto (MG), abr. 2014. p. 2630. Disponível em: <http://www.mineclosuresolutions.com/wp-content/ uploads/2014/05/Scalon-Marina-Have-the-international-guidelines-for-mineclosure-been-internalized-by-the-Brazilian-legal-framework.pdf $>$. Acesso em: 18 ago. 2014.

SOARES, L. Barragem de rejeitos. In: Tratamento de minérios. 5. ed. Rio de Janeiro: CETEM/MCT, 2010. p. 829-896. 
SOUZA, M. G. Fechamento de mina: aspectos legais. Geólogo.com.br, 2003. Disponível em: <http://www.geologo.com.br/fechamentomina.htm>. Acesso em: 17 jun. 2019.

TAVEIRA, A. L. S. Provisão de recursos financeiros para o fechamento de empreendimentos mineiros. Tese (Doutorado) - Escola Politécnica, Universidade de São Paulo, São Paulo, 2003.

THOMÉ, R. Manual de Direito Ambiental. 9. ed. Salvador: Juspodivm, 2019. THOMÉ, R. O princípio da vedação de retrocesso socioambiental no contexto da sociedade de risco. Salvador: Juspodivm, 2014.

TOLEDO, A. P.; RIBEIRO, J. C. J.; THOMÉ, R. Acidentes com barragens de rejeitos da mineração e o princípio da prevenção: de Trento (Itália) a Mariana (Brasil). Rio de Janeiro: Lumen Juris, 2016.

VALE ANUNCIA US\$ 1,9 bilhão para acelerar descomissionamento de barragens. Estado de Minas, 8 jun. 2019. Disponível em: <https://www. em.com.br/app/noticia/gerais/2019/06/08/interna_gerais, 1060282/valeanuncia-us-1-9-bilhao-para-acelerar-descomissionamento-de-barrag.shtml $>$. Acesso em: 11 jun. 2019.

Artigo recebido em: 21/06/2019.

Artigo aceito em: 26/08/2019.

\section{Como citar este artigo (ABNT):}

THOMÉ, R.; RIBEIRO, L. G. G. A descaracterização de barragens de rejeito e o plano de fechamento de mina como instrumentos de mitigação de riscos na mineração. Veredas do Direito, Belo Horizonte, v. 16, n. 35, p. 63-85, maio/ ago. 2019. Disponível em: <http://www.domhelder.edu.br/revista/index.php/ veredas/article/view/1567>. Acesso em: dia mês. ano. 